Using photography to understand the urban phenomena. Methodological transfers, visual ethnography in the architectural classroom

| RESUMEN |

El fenómeno urbano ha sido abordado desde variados y distintos enfoques y aproximaciones metodológicas; sin embargo, la condición subyacente de la experiencia de habitar las ciudades permanece esquiva en una gran cantidad de ellos. El presente artículo pretende traer a la discusión la idea de experiencia urbana y, mediante una aproximación etnográfica visual transferida desde la antropología, permitir una apertura a nuevas formas de problematizar lo urbano dentro del contexto académico.

\section{| ABSTRACT |}

The urban phenomenon has been dealt with from a variety of different points of view and methodological approaches; however, the underlying condition of the experience of living in cities remains elusive to a lot of them. This article intends to bring to the discussion the idea of urban experience through a visual ethnographic approach, transferred from anthropology, opening new ways to problematize the urban issue within the academic context.

LUIS ITURRA MUÑOZ*

\title{
El uso de la fotografía para problematizar lo urbano. Transferencias metodológicas, etnografía visual en la enseñanza de arquitectura*
}

\section{INTRODUCCIÓN}

Abordar el fenómeno urbano lleva consigo la carga de la problematización inicial, ¿̇cómo este es comprendido por los investigadores, académicos o no académicos? ¿̇cómo es planteada esta aproximación inicial? ¿̇cómo es explorado?

Este artículo combinará la idea del trabajo con fotografías y de la labor con la experiencia urbana, y utilizará como material de estudio trabajos visuales realizados por estudiantes de la Facultad de Arquitectura y Urbanismo de la Universidad de Chile; mediante estos, se abordarán problemáticas y cuestionamientos referente a la ciudad que habitualmente pasan desapercibidos, pero que se constituyen como una parte fundamental de la comprensión del habitar en ciudades.

\section{OBSERVAR LO URBANO}

Trabajar con lo urbano, sin duda posiciona este escrito dentro del trabajo con la ciudad, y tangencialmente toca al urbanismo como disciplina. Es por este motivo que resulta pertinente establecer las bases del cambio en la forma de concebir la ciudad que viene sucediendo desde la segunda mitad del siglo $X X$, para de este modo establecer la forma en la cual será comprendido lo urbano en este texto y permitirá relacionar la transferencia metodológica que significa el uso de métodos visuales para comprenderlo y problematizarlo.

Habitualmente al hablar de la ciudad se hace referencia a su condición material y su vinculación con una determinada espacialidad, o a una abstracción estadística de su conformación, es decir una reducción numérica de su complejidad. Cuando se habla de espacio o espacialidad, la discusión se enfrenta

* Arquitecto, Magíster en Hábitat Residencial y Docente de la Facultad de Arquitectura y Urbanismo de la Universidad de Chile. Ha realizado investigaciones que vinculan las problemáticas urbanas con metodologías visuales que capturen la experiencia de vivir en ciudades. Actualmente es parte del comité organizador de la conferencia internacional "Uneven Mobilities 2014".

** Agradecimientos. Este artículo proviene del curso FG FAU "La fotografía una forma de explorar la ciudad", el cual fue concebido en un estado inicial junto a Paola Jirón y Walter Imilan, y de la discusión con ellos se genera la plataforma metodológica del curso actual. No hubiese sido posible además, sin la traducción de los textos de Simmel y Weber por parte de Walter Imilan. Gracias al trabajo y dedicación de los estudiantes del curso en su totalidad. 
con una fragmentación, de este modo, se estudian parcialidades del espacio de la ciudad utilizando para ello la disección en determinados componentes materiales, morfológicos, etc., lo que Lefebvre establece como los fragmentos en los cuales las ciencias tienen que reducir la totalidad para estudiarlos con cada uno de sus métodos (Lefebvre, 1974). Del mismo modo, las disciplinas que han estudiado la ciudad y su devenir histórico con leyes de grandes números solo han podido describir una porción de aquello de lo que está formada la ciudad, sin embargo al dejar de lado las diferencias, individualidades, y excepcionalidades, y habiendo dejado de lado el comportamiento cotidiano excluido como falto de importancia (Arendt, 1958 2009) se ha destruido la materia de las relaciones diarias que articulan y dan forma a la ciudad.

En efecto, el urbanismo como disciplina que estudia y proyecta la ciudad, ha formulado los problemas de las sociedades en términos espaciales (Lefebvre,1978) y a su vez, las ciencias sociales han trabajado tradicionalmente sobre el fenómeno urbano a partir de una distinción central: lo físico-espacial por un lado, y lo sociocultural por otro.

La dimensión física material de la ciudad ha sido entendido como urbanización (Weber, 2006; Simmel, 2006) a principios del siglo XX; y las dinámicas sociales y culturales que surgen de la ciudad, tematizadas bajo la noción de urbanidad (Weber, 2006) o urbanism as a way of life (Wirth, 1938). Así, la urbanización se trabaja siguiendo el esquema funcionalista que "reduce a la sociedad urbana a la ejecución de algunas funciones previstas y descritas sobre el terreno de la arquitectura" (Lefebvre, 1978: 60) y, las dinámicas espaciales, se han traducido en información estadística de lo social, o poblaciones independiente de los espacios que habitan relegándolos a telón de fondo de las prácticas humanas (Hannerz, 1980; Ortiz, 1996; Soja, 2011).

En esta complejidad y fragmentación, entonces, ¿Qué es lo observable cuando se habla de lo urbano? Para responder esta pregunta es necesario situarse dentro de las nuevas formas de concebir la espacialidad, estas provienen teóricamente desde la actualizada discusión de la geografía contemporánea, por ejemplo, la desarrollada por Massey, quien plantea que un espacio es el producto de interrelaciones, posibilitador de la existencia de multiplicidad, siempre en proceso de construcción (Massey, 2005). Esta nueva noción de un espacio inacabado, siempre deviniendo, es posible vincularlo a la idea de "de-territorialización", la cual no habita en un territorio teórico, sino que puede observarse en el campo del trabajo, donde las personas se vuelven continuamente móviles y "empleados remotos y consultores están trabajando más desde sus casas y disolviendo las fronteras entre trabajo y hogar" (Jordan, 2009); o re-conceptualizando las visiones en la dualidad público/privado y, más que una posición en un territorio estático se enfatiza la fluidez en términos de dónde y cuándo ocurren los momentos públicos o privados (Sheller y Urry, 2003).

Es el habitante de la ciudad, entonces el que hace cuerpo lo urbano, quien lo encarna y quien se establece como el sujeto que relata el devenir y la construcción de la urbanidad. Es por lo tanto desde el habitante, o hacia el habitante, que la ciudad es observada, y lo urbano, por lo tanto, emerge como una fenómeno que es posible develar desde la observación de como las personas habitan en las ciudades y crean lugares en ella (lturra, 2014; Jiron e lturra, $2011)$.

\section{TRABAJANDO CON LA EXPERIENCIA}

La experiencia permite observar el fenómeno urbano poniendo atención a la urbanización y urbanidad como una interrelación que pone al habitante en el centro. Así, la experiencia revela lo dinámico que está anclado en el lado activo de las relaciones humanas permitiendo observar a los actores, individuos u organizaciones, y la manera cómo estructuran las relaciones entre las diferentes situaciones que atraviesan (Bourdin, 2005; citado en Duhau y Giglia, 2008). El fenómeno urbano observado desde la experiencia, plantea el problema metodológico de su captura, develación y representación.

En la intuición y la habilidad traspasada en el oficio de la arquitectura a los estudiantes, existe y persiste una forma particular de observar la realidad; a modo de hipótesis sería posible plantear que la observación arquitectónica de la realidad forjada y anclada en la repetición, la prueba y el error, forjando una relación entre repetición y práctica que es a menudo acompañada de una forma de representación visual o tridimensional. Tal como un artesano, el arquitecto "Piensa y hace al mismo tiempo, dibuja y hace. El dibujo... es revisado. Lo haces, lo re-haces y lo vuelves a hacer" (Sennet, 2008: 57); así volver una y otra vez en continua repetición permite autocrítica y retroalimentación a la observación inicial.

Sin embargo, esta habilidad dada por el oficio, para trabajar con la experiencia de fenómeno urbano, debe ser guiada y enmarcada dentro de una metodología que permita trabajar con ella y evolucionar con esta forma particular de observación; así, comprendiendo la experiencia como un fenómeno en sí mismo, es necesario recurrir a metodologías de registro fenomenológico provenientes de otras disciplinas. La etnografía, surge así relevante por su particularidad de hacer visible la acción de los sujetos en la construcción de su entorno (Imilan, 2011), y por el involucrar las maneras de hacer, mirar y escribir como un todo, influenciando directamente la información que es recolectada (Jirón, 2008); la etnografía comprendida entonces como un rango amplio de prácticas de investigación cualitativa, que pueden incluir observación activa, entrevista etnográfica, y otras técnicas de investigación participativa que necesitan adaptarse y desarrollarse según el contexto (Sarah Pink, 2009).

Vinculada a la observación arquitectónica, la aproximación etnográfica está basada en la importancia central de la noción de reflexividad, que reconoce la subjetividad del observador en la producción y representación del conocimiento; así la repetición y la prueba, 
1. ¿Qué sucede en la noche cuando no existen vías especiales para bicicletas, cómo se experiencia este viaje a través de la ciudad? Fuente: Rocío Palma.

2. ¿Cómo se presenta este paisaje urbano donde la máquina es el soporte visible de la infraestructura? Fuente: Franco Besoain.
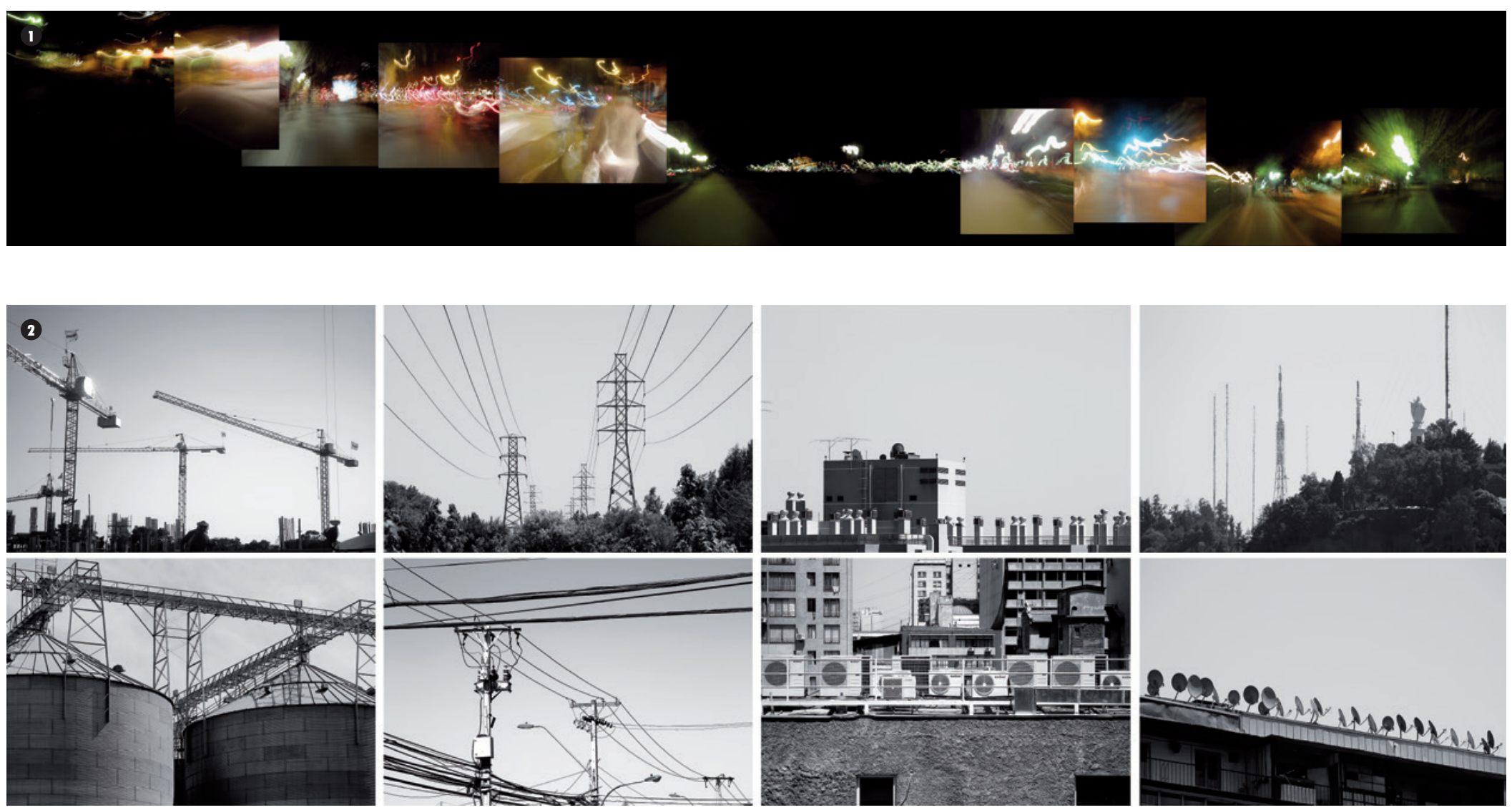

la continua evolución del proceso de observar, es rápidamente incorporado en la discusión del fenómeno urbano permitiendo pensar y hacer al mismo tiempo, problematizando mientras se observa y generando conocimiento mientras se representa. Esto se vuelve particularmente relevante al asociar el problema de la intuición en la enseñanza de la arquitectura, pues el enfoque fenomenológico que fundamenta la etnografía, responde a un cambio filosófico de la concepción de la realidad y, por lo tanto de la forma en la cual el conocimiento y la verdad toman lugar (Rooney, 2005). Este nuevo pensamiento descansa en la premisa epistemológica que la verdad y los significados no existen independientemente, sino que son creados por la mente humana en un nivel personal individual, por lo tanto, "en vez de develar una verdad objetiva, creamos verdad o significado, a través de la conexión con las realidades del mundo" (Crotty, 1998; citado en
Rooney, 2005:4,5); situación que cuestiona el propósito del rol del observador, y los conceptos de objetividad y validez; y en este sentido la verdad objetiva de la realidad no existe, porque la realidad es el producto individual de la conciencia, y por lo tanto, pueden existir realidades múltiples (Ellis y Bochner, 2000; en Rooney, 2005).

Así, observar, es más que una experiencia de mirar, es una experiencia en la luz (Ingold, 2005); lo que Merleau-Ponty llamó "el suelo de lo sensible", es decir, no podemos ver las cosas a menos que estemos inmersos en esta sensibilidad y esta sensibilidad es la luz como una experiencia de ser-estar en el mundo (Heidegger, 2005; Ingold, 2005). La visión no se trata de definir y describir los objetos bajo la luz, como mencionaba Le Corbusier, que es la forma habitual en que los videntes la entendemos; sino que abarca mucho más que eso, por ejemplo, si nos ponemos desde la perspectiva de un ciego que recobra la vista o de un recién nacido que abre los ojos por primera vez, la experiencia de la luz, es la que lo sitúa en el mundo (Ingold, 2006). Merleau-Ponty llamó a esto la magia de la visión, como el sentido de que, a cada momento uno abre los ojos por primera vez hacia un mundo en formación.

\section{TRABAJANDO CON LA FOTOGRAFÍA Y LA EXPERIENCIA VISUAL}

Según Aguilar y Eraña (2008) la visión está compuesta de la experiencia visual y la forma en la cual se tiene esta experiencia, de este modo, la experiencia visual del fenómeno urbano se organiza de acuerdo con el contexto en donde se sitúa. Esto vincula el espacio y el tiempo, la urbanización y lo urbano, así como elemento, la fotografía posee la particularidad de capturar la 
3. Experiencia de vivir próximo a los vecinos en edificios de renovación urbana. Fuente: Hannah Niemand.
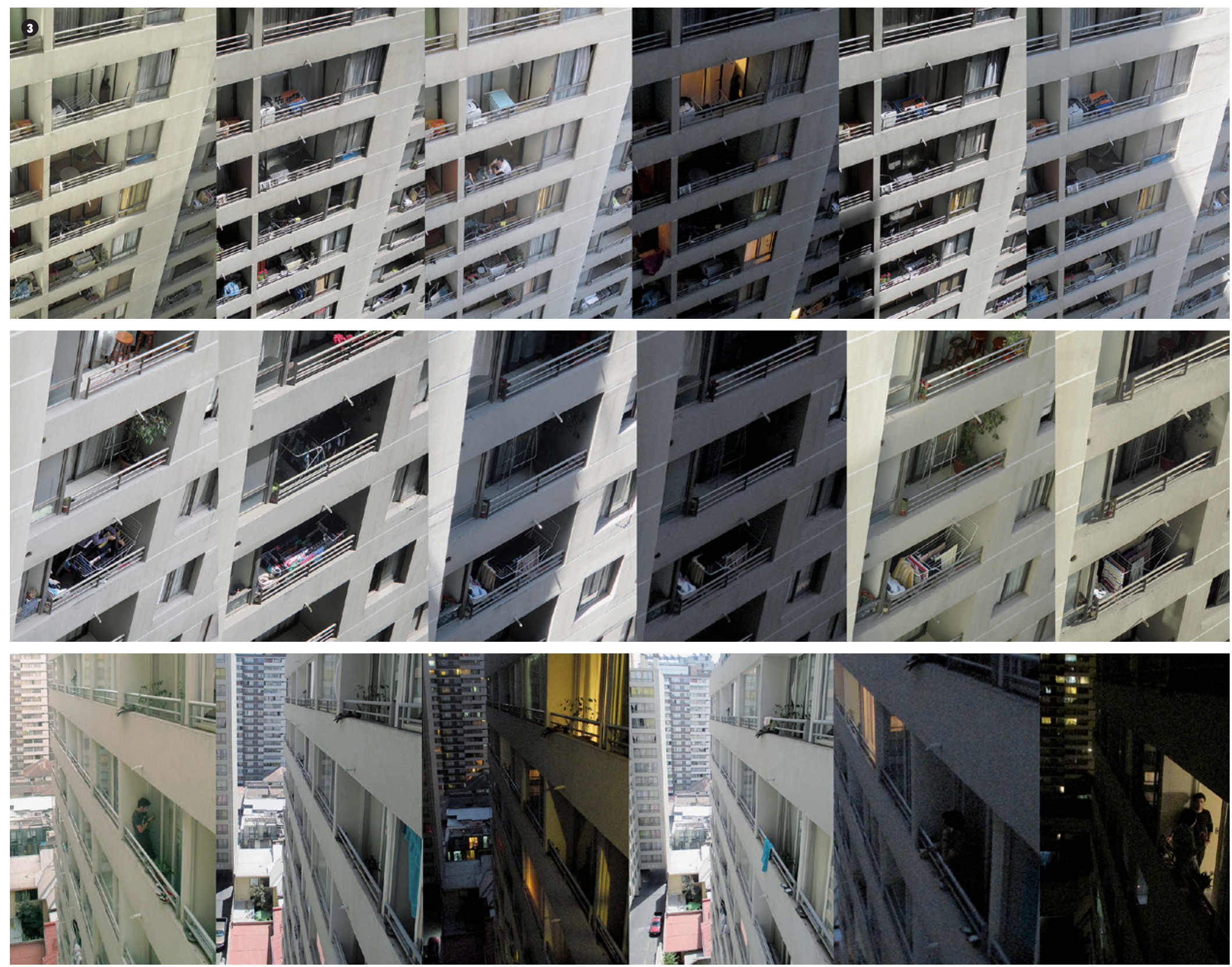

noción del tiempo y la forma del espacio como si se tratase de un "objeto laminar de los que no podemos separar dos láminas sin destruirlos" (Barthes, 2003:31).

La fotografía se constituye, de este modo, como un técnica de captura, la cual escribe con luz -del griego, photo: luz, graphie: escritura-, los "textos" etnográficos que develan la experiencia; y posee un soporte material que permite capturar la experiencia en relación a la existencia urbana, reproduciendo al infinito un evento que ha tenido lugar una sola vez repitiendo "mecánicamente lo que nunca más podrá repetirse existencialmente" (2003:29). Esto posee una conexión personal y es lo relevante de recolectar y capturar, pues la realidad capturada en la fotografía está construida desde la forma particular de observar el fenómeno urbano (Larsen, 2005). Al representar un espacio real, la fotografía muestra necesariamente una selección del espacio representando "un corte plano y parcial de un espacio infinito y tridimensional" (Meraz, 2008:100), estableciendo así una 
4. La conformación de las esquinas en un sector sometido a renovación urbana. Fuente: Yerko Moraga.

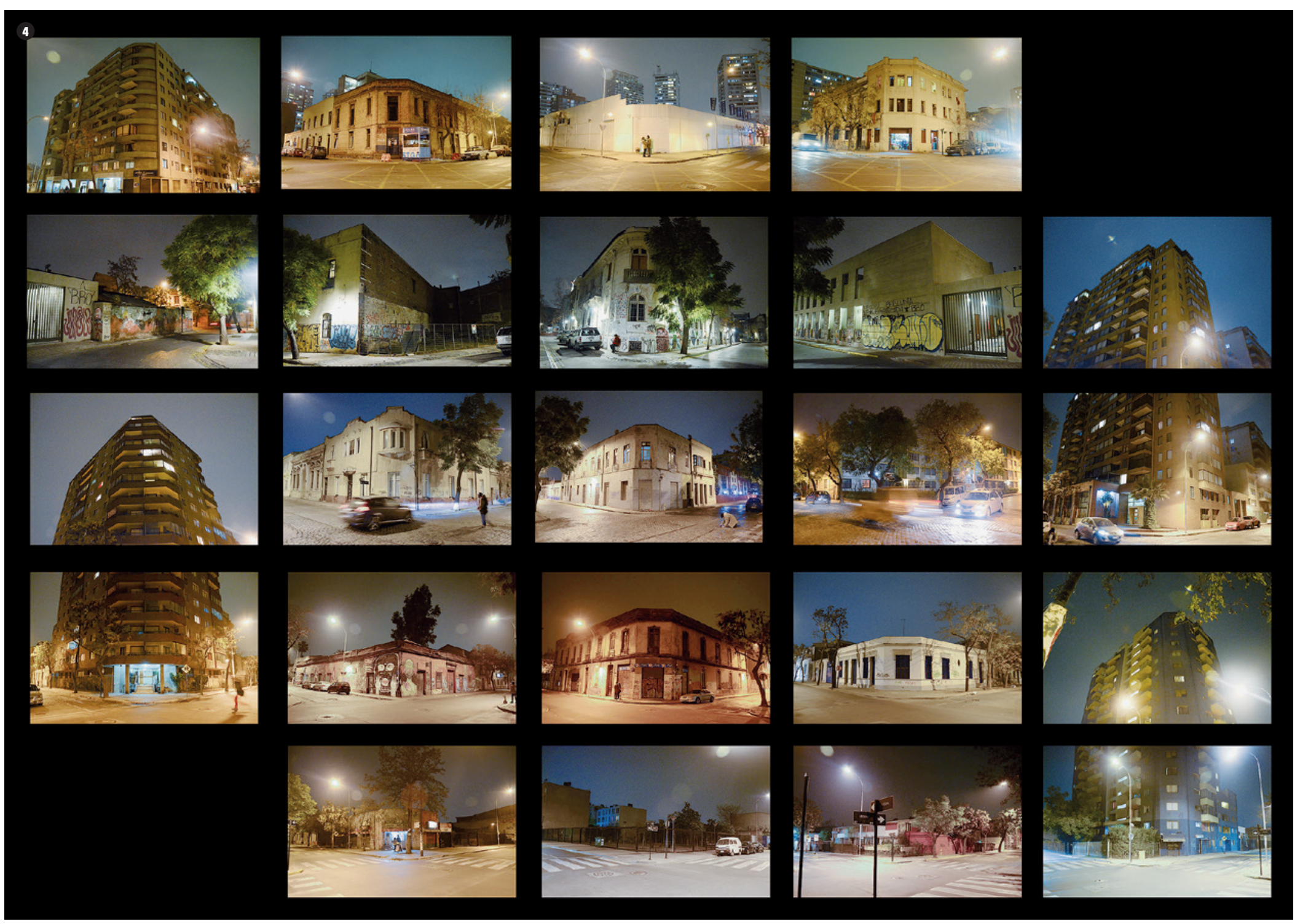

relación entre un espacio representado, que es lo visual del espacio de referencia transferido a la foto; y un espacio de representación, que es la imagen como soporte -la fotografía como elemento visual. Es lo que Barthes (2003) Ilama una reproducción analógica de la realidad, donde se pueden encontrar elementos puntuales que forman parte de esta imagen fotográfica, haciendo "saltar" aquellos detalles y características de la vida que son visibles y que pudieron pasar desapercibidas.

\section{PROBLEMATIZANDO LO URBANO}

Así planteado, utilizando una aproximación etnográfica desde la observación arquitectónica, surge una exploración etnográfica visual que utiliza lo visual presente en la fotografía; esta como elemento, posee la particularidad de ser un cuerpo material presente en la realidad, no es una abstracción, sino un elemento intercambiable, modificable y contrastable, que permite generar discusión desde la observación de lo que ella contiene. En efecto, la fotografía, permite conocer las experiencias particulares de cada uno de los observadores del fenómeno urbano; reconocer sus posiciones socioeconómicas, su género, su etnia, sus problemas y cuestionamientos frente a la ciudad. Carga consigo con los elementos no discursivos que permiten leer aquello que no se ve habitualmente al observar la ciudad, lo cual corresponde en cómo "el otro" observar la misma ciudad que se habita en conjunto. 
5. Cambios de color en el viaje subterráneo del metro. Fuente: Andrea Merino.

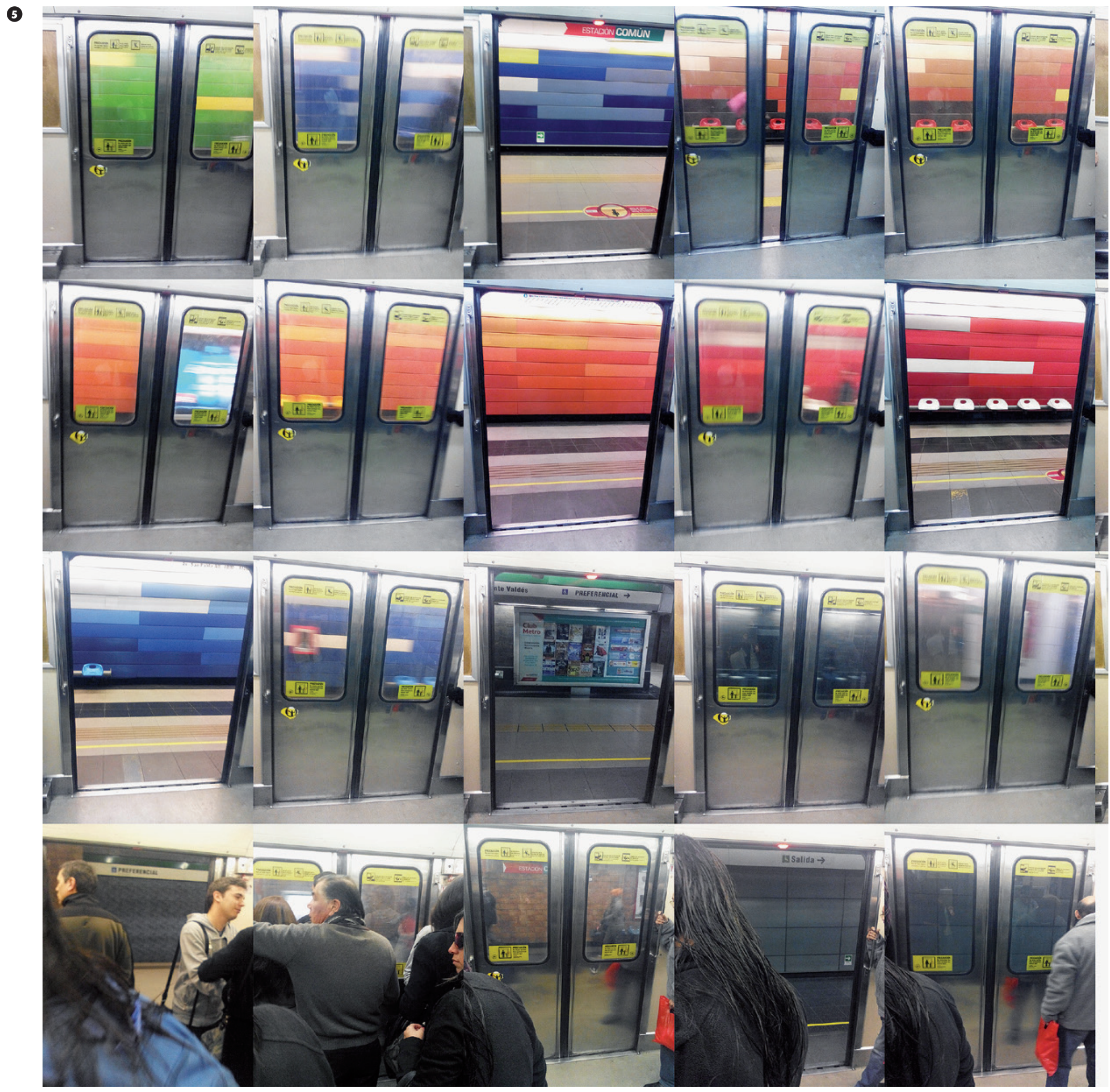


6. Paisaje visual de la propaganda y la ironía de su relación con la publicidad existente. Fuente: Florencia Menceyra.
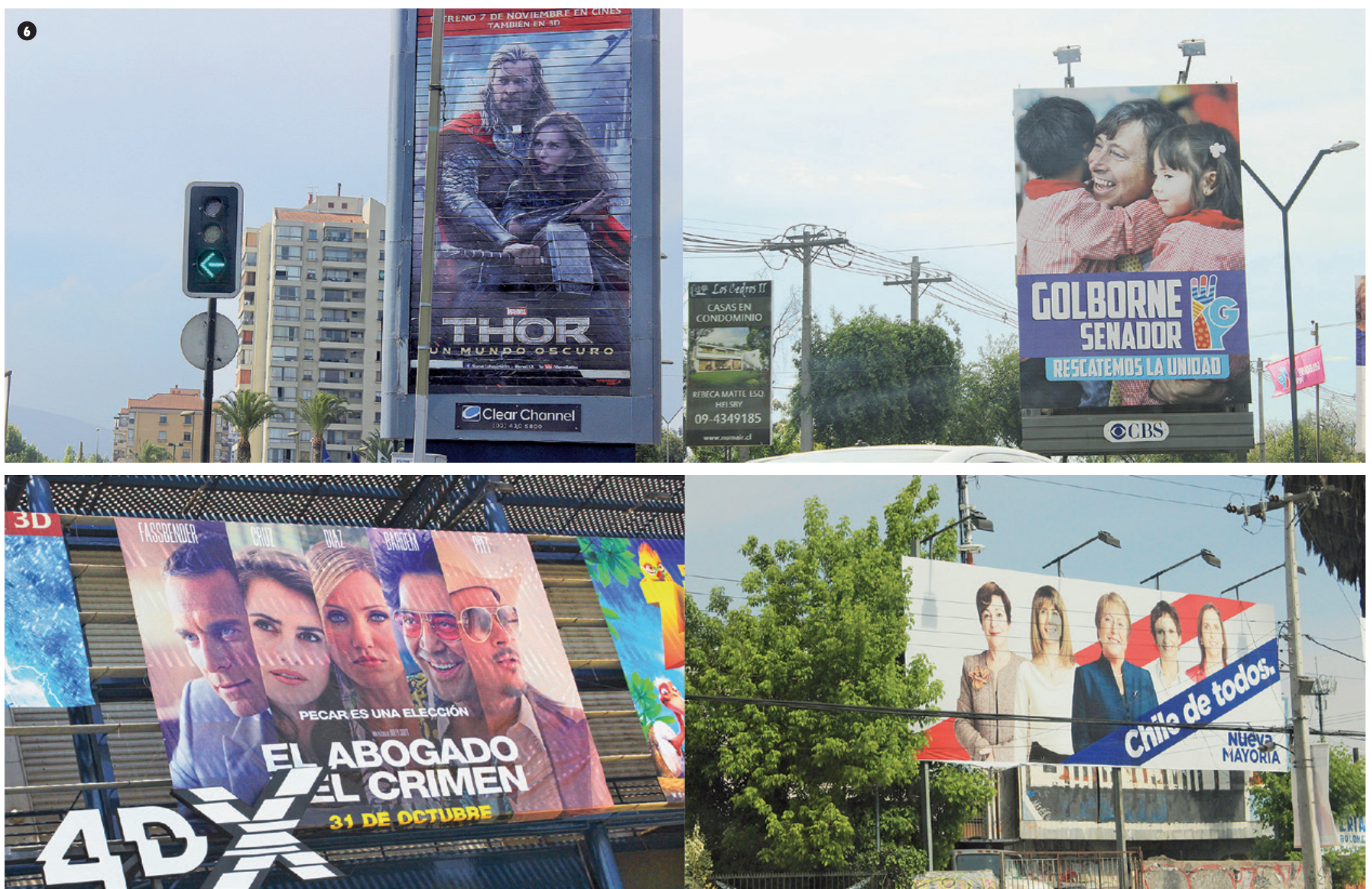

La problematización del fenómeno urbano, aparece entonces como una discusión centrada en la carga semántica de cada imagen, la cual proviene de observadores de diferentes disciplinas, con distintas historias de vida y con diversas aproximaciones a la ciudad; dentro de esta discusión el fenómeno urbano emerge paulatinamente. Cada vez el observador centra y jerarquiza su captura fotográfica, recorta la realidad y apunta a lo que determinada situación urbana, relacionada con su experiencia, es capaz de aportar a una discusión más amplia; en esta discusión las distintas experiencias retratadas expuestas lado a lado y comparadas, logran generar diversas y particulares aproximaciones al fenómeno urbano que son posibles de ser problematizadas dentro de una discusión más amplia.

\section{LA FOTOGRAFÍA COMO FORMA DE EXPLORAR LA CIUDAD}

Para exponer lo anterior se expondrán una serie de imágenes que buscan problematizar el fenómeno urbano desde un punto de vista particular, enmarcándose en discusiones más amplias y contemporáneas.
Si por ejemplo, se utiliza la premisa inicial de este artículo y la relación con el urbanismo como disciplina ideológica que ha intervenido en la ciudad considerando la realidad de una forma parcial, aparece la discusión teórica contemporánea del urbanismo astillado -splintering urbanism- (Graham y Marvin, 2001); la ciudad presenta diferencias en su conformación física dadas por la creación de infraestructura no coordinada. Esto habitualmente sería representado por los investigadores urbanos con datos estadísticos - levantamientos planimétricos que permitan comprender esta ruptura. Sin embargo, al 
7. Nuevas formas de paisaje urbano en el centro histórico dado por los reflejos de las edificaciones. Fuente: Hernán Cerda.

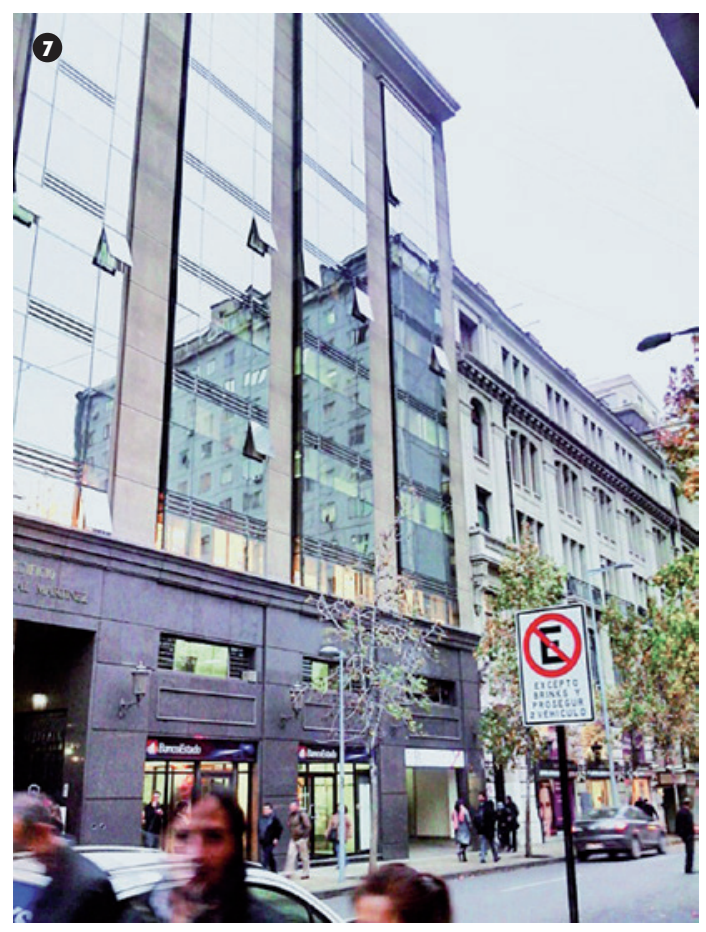

trabajar desde la experiencia emerge la visión del habitante y la problematización sucede en forma de pregunta, por ejemplo, ¿̇cuál es la experiencia de viaje, durante la noche cuando no existen vías especiales para bicicletas?, ¿̇cómo se presenta este paisaje urbano donde la máquina es el soporte visible de la infraestructura?

Considerando otra variable del fenómeno urbano tradicionalmente estudiado, como es la edificación en altura de vivienda en los centros metropolitanos, habitualmente han sido estudiados utilizando un análisis desde la brecha en el precio del suelo-Rent Gap-. Al observar este proceso mediante la fotografía como exploración de la experiencia de habitar, surgen preguntas como, żcuál es la relación que se establece con los vecinos cuando se vive tan próximo?, ¿̇cómo se modifican las esquinas urbanas por este proceso?

Cambiando el eje, se articula la discusión desde aproximaciones subjetivas al fenómeno urbano, como es por ejemplo los imaginarios
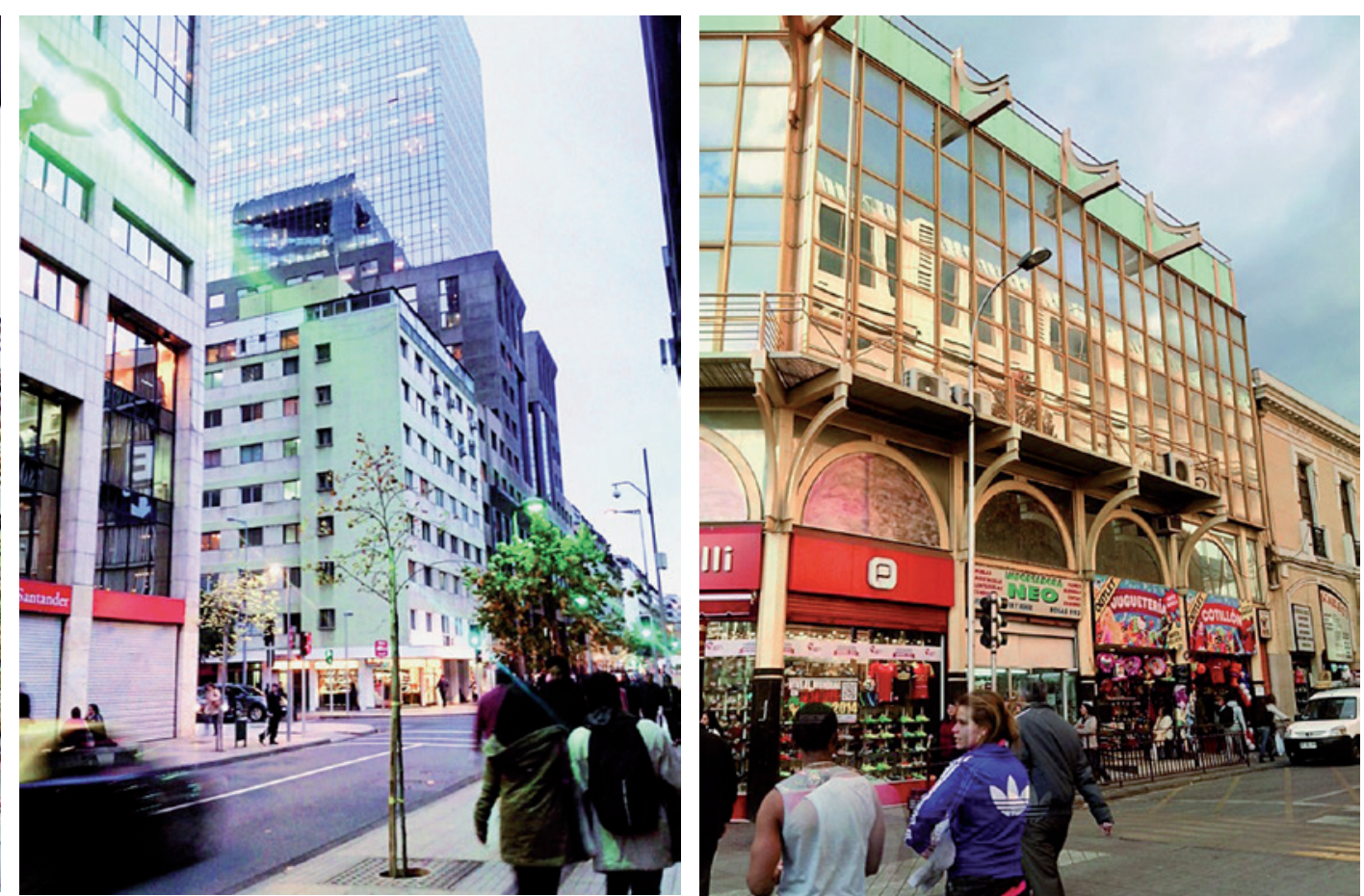

urbanos o la idea de paisaje. Aparece la forma en la cual ciertas infraestructuras colorean la experiencia de habitar las ciudades y es posible reconocer los lugares donde se está en la ciudad aún en el transporte subterráneo; o también como el paisaje urbano es modificado por elementos visuales como la propaganda política, que sin embargo no es otra cosa que una continuidad del paisaje visual imperante; o como, perceptualmente los reflejos en las construcciones permiten habitar una ciudad donde lo material se hace invisible.

\section{CONCLUSIONES}

La fotografía como elemento de exploración del fenómeno urbano, permite describir la realidad y trabajar con ella de un modo en el cual los estudiantes de arquitectura están habituados. La prueba y el error, la repetición, la creación de la discusión a partir del oficio de hacer, producen que la etnografía como método y la fotografía como técnica, son posibles de ser comprendidas y utilizadas para discutir la ciudad y situar su problematización en un universo de discusión más amplio.

Al mismo tiempo, permite cargar con el elemento de registro sin importar la naturaleza de este dispositivo, por lo tanto, se centra en capturar lo más fielmente posible el fenómeno urbano y producir preguntas que permitan explorarlo.

\section{BIBLIOGRAFÍA}

Aguilar, J., \& Eraña, Á. (2008). “Los problemas ontológico y epistemológico en el fotoperiodismo. Veracidad y objetividad". En I. de la Peña (Ed.), Ética, Poética y Prosaica: Ensayos Sobre Madrid: Siglo XXI.

Arendt, H. (2009). La condición humana (R. Gil, Trans. $1^{\text {ra }}$ ed, $5^{\text {ta }}$ reimpresión ed.). Buenos Aires: Paidós. Barthes, R. (2003). La cámara lúcida. Buenos Aires: Paidós.

Graham, S. y Marvin, S. (2001). Splintering Urbanism. Londres: Routledge. Fotografía Documental. México, Buenos Aires, 
Hannerz, U. (1980). Exploring the city. Inquieries Toward an Urban Anthropology. New York: Columbia University Press.

Heidegger, M. (2005). Ser y tiempo (4 $4^{\text {ta }}$ edición ed.). Santiago: Editorial Universitaria.

Ingold, T. (2005). "The eye of the storm: visual perception and the weather". En Visual Studies, 20(2). Londres: Taylor \& Francis Group

Imilan, W. (201 1). "Experiencia de la ciudad a través de la movilidad. Una mirada etnográfica". Paper presentado en Pre Conferencia UGI Valparaíso: Fenómenos Informales Clásicos en la Megaciudad Latinoamericana, Universidad Técnica Federico Santa María. Departamento de Arquitectura.

Ingold, T. (2006). "Up, across and along". En Place and Location. Studies in Enviromental Aesthetics and Semiotics, 5, 21-36.

Iturra M., L. “¿¿Dónde termina mi casa? Mirando el hábitat residencial desde la noción de experiencia". Revista INVI,29(81). Santiago: Instituto de la Vivienda, Facultad de Arquitectura y Urbanismo, Universidad de Chile. http:// www.revistainvi.uchile.cl/index.php/INVI/article/ view/835
Jirón, P. (2008). Mobility on the Move: Examining Urban Daily Mobility Practices in Santiago de Chile. PhD, London School of Economics and Political Science, London.

Jirón, P., e lturra, L. (201 1). "Momentos Móviles. Los lugares móviles y la nueva construcción del espacio público". En Arquitecturas del Sur (39), 44-45. Universidad del Bío-Bío

Jordan, B. (2009). "Living 'In-Between'". En FO the Spirituality and mobility issue, 2.

Larsen, J. (2005). "Families Seen Sightseeing: Performativity of Tourist Photography". En Space and Culture, 8(4), 416-434.

Lefebvre, H. (1978). El Derecho a la Ciudad. Barcelona: Provenca.

Massey, D. (2005). For space. Londres: SAGE.

Meraz, G. (2008). Trompe-L'oeil. En I. de la Peña (Ed.), Ética, Poética y Prosaica: Ensayos Sobre Fotografía Documental. México, Buenos Aires, Madrid: Siglo XXI.

Merleau-Ponty, M. (2008). The World of Perception (O. Davis, Trans.). Londres, Nueva York: Routledge.

Ortiz, R. (1996). Otro territorio: ensayos sobre el mundo contemporáneo. Buenos Aires: Universidad Nacional de Quilmes.
Perec, G. (2001). Especies de espacios. Barcelona: Editorial Montesinos.

Pink, S. (2009). Doing sensory ethnography. Londres: Thousand Oaks, CA: Sage.

Rooney, P. (2005). "Researching from the inside - does it compromise validity? - A discussion". En Level 3(3).

Sheller, M., Urry, J. (2003). "Mobile Transformation of 'Public' and 'Private' Life". En Theory Culture and Society, 20(3).

Simmel, G. (1903). Die Gorßsta-dte und das Geistesleben. Frankfurt: Suhrkamp.

Soja, E. W. (2011). Postmodern Geographies: The Reassertion of Space in Critical Social Theory. New York: Verso.

Weber, M. (1922). Wirtschaft und Gesellschaft. Munster: Paderborn.

Wirth, L. (1938). Urbanism as Way of Life. En The American Journal of Sociology, 44(1): 1-24. 